\title{
DANÇA DO VENTRE: EVOLUÇÕES E PROPOSIÇÕES DE UMA DÉCADA ${ }^{1}$
}

\author{
Odilon José Roble
}

Universidade Estadual de Campinas, Campinas, São Paulo, Brasil

Karen Adrie de Lima

Universidade Estadual de Campinas, Campinas, São Paulo, Brasil

\begin{abstract}
Resumo
Esse trabalho focou a Dança do Ventre no país na última década. Para isso, aplicamos uma entrevista semi-estruturada em onze sujeitos envolvidos com a modalidade a mais de 10 anos e operamos uma Análise de Conteúdo, tal como proposto por BARDIN (2010). Os resultados obtidos atestam sensível evolução nas formas de conceber a estética da Dança do Ventre em território nacional na última década, subsidiada, em especial, pela notável disseminação da modalidade, pela facilidade de acesso à informação como a propiciada pela internet, e pela popularização alcançada a partir de novelas e filmes. Os resultados obtidos foram comparados com os de Trevisan (2000), de modo a obter mais um indicativo da evolução que investigamos.
\end{abstract}

Palavras-chave: Dança. Midia Audiovisual. Estética.

\section{Introdução}

$\square$ ssa pesquisa teve como objetivo central diagnosticar uma possível mudança nas formas de pensar e agir na Dança do Ventre praticada no Brasil nos últimos dez anos. Para tanto, revisitou os dados de Trevisan (2000) e lançou mão de um novo processo de entrevistas com mais onze sujeitos que lecionam Dança do Ventre a mais de dez anos. Ao compararmos os resultados obtidos por Trevisan (2000) com os nossos, e à luz da literatura recente sobre o tema, inferimos alguns indícios que revelam a evolução dessa arte em solo brasileiro em tal intervalo de tempo, argumentando também sobre as possíveis razões que levaram à essa nova configuração. Ao utilizarmos o termo evolução, esclarecemos que fazemos uso de uma acepção na qual a palavra designa um processo gradativo de transformação,

1- Esta pesquisa contou com o apoio do CNPQ. 
para que assim não seja tomada como, necessariamente, sinônima de ganho qualitativo ou quantitativo sob qualquer parâmetro.

Uma vez que o objeto em exame é uma forma de arte, torna-se necessária uma reflexão prévia que situe conteúdo e forma dessa modalidade, de modo a consubstanciar-se à análise e produzir uma interpretação preocupada em manter o valor artístico do fenômeno o mais preservado possível. Para tal, vejamos de partida as origens e conceitos comumente associados à Dança do Ventre e expressos em sua produção de conhecimento recente, assim como as abordagens teóricas de sua prática no Brasil e no mundo.

\section{Origens e conceitos}

Precisar a origem da Dança do Ventre, principalmente devido ao intercâmbio entre as culturas da região, é considerado muito difícil (BÉRGAMO, 2003). Há indícios de ocorrências de danças como ritos de passagem da puberdade na África; de danças compostas por ondulação de quadril e rotação pélvica na Grécia antiga e de festivais de adoração às deusas do Egito e Líbano, que entre outras, compõem um quadro de possíveis influências e analogias à Dança do Ventre (CENCI, 2001).

Do ponto de vista social, além de encontrar-se inserida em culturas muito complexas, sabe-se que a Dança do Ventre era praticada por sacerdotisas, passada de mães para filhas e que possuía caráter sagrado, uma vez que integrava rituais femininos de culto às deusas da fertilidade, tais como Îsis (LA REGINA, 1998). Penna (1993), também aponta uma ligação para os ritos sagrados e de fertilização, denominando essas passagens como atos de honra à Grande Mãe (Inana); Marató (2006) defende que esta dança é uma mistura de elementos religiosos e eróticos vindos dos cultos às deusas mães das primeiras culturas orientais. Mohamed (1995), por sua vez, denomina esta dança como "dança mágica" devido ao profundo sentimento de comunicação interior que ela viabiliza.

Diante desse cenário, é muito comum reduzir as danças orientais à Dança do Ventre, o que caracteriza um equívoco, uma vez que existem a japonesa, a indiana, entre outras (CENCI, 2001). Neste aspecto,

há de se considerar que nem todas as danças pré-históricas, 
danças da antiguidade ou até mesmo danças dos países árabes podem ser consideradas dança do ventre. Dança do ventre é apenas uma das danças existentes no Oriente Médio; não sendo os movimentos de quadril e ventre exclusivos da dança do ventre (FRANZOSI, 2009, p. 10).

Ao abordar a modalidade em questão sob um aspecto mais técnico, num conceito específico desta arte, Martins (2005) diz que a Dança do Ventre apresenta uma subdivisão de três estilos: o clássico, que é a Dança do Ventre tradicional, a qual funde diversos estilos da região; o folclórico, que se baseia no folclore regional e frequentemente apresenta-se regrado e, por fim, o moderno, que costuma mesclar os traços do ocidente com o oriente. Franzosi (2009) enfatiza que o chamado "universalismo europeu" influenciou diretamente nas formas de viver, pensar e agir no contexto da Dança do Ventre.

Faz-se cada vez mais perceptível a produção de conhecimento pautada nos benefícios que esta dança pode proporcionar. Entretanto, como aponta Franzosi (2009), essa produção de conhecimento, por estar ainda muito atrelada a um interesse de divulgação da modalidade para fins comerciais, costuma assumir uma linguagem tendenciosa. Outra característica comumente encontrada na produção de conhecimento em torno da Dança do Ventre é a sua relação com o sagrado. O caráter sagrado da Dança do Ventre foi mais evidente em uma época distinta da atual, na qual, entre outras características, a sociedade antiga era em grande parte politeísta e fortemente esotérica. Por fim, podemos notar ainda alguma produção relativa aos benefícios orgânicos e de saúde, por se tratar de uma atividade física, originalmente voltada para o corpo da mulher (CANTÚSIO, 2003) e que assim como outras, deve proporcionar qualidade de vida.

Enfim, diante da literatura atual, constatamos que os estudos ainda são incipientes, com focos de atenção muito dispersos e interesses nem sempre científicos, ainda que uma produção mais significante venha se avolumando. Acerca dos conceitos, valores e práticas parece haver, cada vez mais, produção de conhecimento a respeito do tema e esta produção parece que vem sendo absorvida pelos praticantes. Um dos objetivos desse estudo reside, justamente, em identificar tal absorção. 


\section{Materiais e métodos}

A proposta para a presente pesquisa apresentou como objetivo principal verificar a evolução nas formas de pensar e agir sobre a prática da Dança do Ventre nas cidades de São Paulo, Campinas, Jundiaí, Mogi Guaçu e Mogi Mirim.

Durante o decorrer da pesquisa, constatamos que o termo "evolução" daria margem a inúmeras interpretações, contudo, visto que de acordo com Ferreira (2008) seria uma sucessão de acontecimentos em que cada um está condicionado pelo anterior ou processo de transformação em que certos elementos simples se tornam aos poucos mais complexos ou mais pronunciados; evidenciamos que, para a presente proposta, nos é pertinente tal apropriação.

Como metodologia, foi utilizada uma comparação entre dados colhidos há cerca de dez anos atrás, por meio da pesquisa de Trevisan (2000), com dados que obtivemos a partir da reaplicação do mesmo instrumento. Para analisarmos os resultados, atualizamos os procedimentos, adotando-se referências como Bardin (2010), que nos permite uma análise de conteúdo sem, contudo, opor-se à linha teórica de Gil (1991), que foi o autor base de Trevisan.

Uma vez que o trabalho consistiu na reaplicação de um instrumento de pesquisa com posterior atualização contextual, empregamos a pesquisa de campo nos mesmos cenários que foram selecionados pela pesquisa original (São Paulo e Jundiaí) e, de forma complementar, no intuito de ampliar o escopo, aplicamos esse mesmo instrumento nas cidades de Campinas, Mogi Mirim e Mogi Guaçu. Ressalte-se que a pesquisa original (TREVISAN, 2000) contou com seis sujeitos e que, para esta versão, propomos doze sujeitos a fim de tentarmos manter o máximo possível a proximidade metodológica escolhida pela autora, mas ao mesmo tempo, propor uma atualização contextual da temática e ampliação dos dados.

Adotamos a regra de serem entrevistadas apenas pessoas que atuassem no mercado de trabalho a mais de dez anos e que, além disso, as entrevistas teriam obrigatoriamente o áudio gravado para posterior transcrição - ambas as estratégias foram estabelecidas a fim de garantir a fidedignidade da pesquisa - foram entrevistados onze sujeitos, estando dispostos um em Mogi Mirim, dois em Jundiaí, três em Campinas e cinco em São Paulo. Esclarecemos que o décimo segundo sujeito recusou-se a conceder a entrevista. O áudio foi captado por uma 
câmera filmadora digital Sony DCP-PJ5 e posteriormente transcrito, compondo 270 páginas de depoimentos. Todos os procedimentos da pesquisa, os roteiros de entrevista e os termos de consentimento livre e esclarecido foram submetidos ao Comitê de Ética em Pesquisa da Faculdade de Ciências Médicas da Unicamp, obtendo o parecer favorável $N^{\circ} 149 / 2011$. Os resultados a seguir expressam o tratamento metodológico aplicado, subsidiando nossas análises posteriores.

\section{Resultados}

Inspirando-nos em um norte metodológico como o proposto por Bardin (2010), em um primeiro momento efetuamos uma discussão temática sobre a Dança do Ventre, subsidiada entre outros, pela produção acadêmica desses dez anos de intervalo; a formulação da hipótese provisória que norteou a pesquisa (se houve ou não evolução nas formas de pensar e agir sobre a Dança do Ventre, na última década); a escolha dos entrevistados de modo a satisfazer a hipótese provisória (por isso a obrigatoriedade de no mínimo dez anos de atuação) e a aplicação dos questionários, seguida das transcrições. Em um segundo momento, efetuou-se a leitura flutuante, a regra de recorte por repetição e a exploração deste material a fim de constituir células para as inferências finais.

Como também foi parte do objetivo rediscutir o fenômeno à luz da constatação de que, ao longo desse período, houve sensível exposição dessa prática por meio dos veículos de comunicação e da mídia, durante a utilização da regra de recorte foram elencadas hipóteses para justificar os objetivos da presente pesquisa, foram elas (1) a mídia; (2) posturas críticas; (3) proposições e (4) disseminação da modalidade. Estes pontos foram alcançados após a transformação das Unidades de Contexto (segmento bruto do texto) em Unidades de Registro e destas em Subcategorias.

Em um primeiro momento de tratamento dos dados, todas as entrevistas foram transcritas. A partir dessa transcrição, passamos a analisar o material, destacando segmentos das entrevistas que seguiam a regra básica de recorte da convergência, ou seja, destacamos trechos das entrevistas que apresentavam dados semelhantes, possíveis de serem posteriormente reduzidos a Unidades de Registro.

Segue, a título de exemplo, uma das onze tabelas que representam a redução da Unidade de Contexto para Unidade de Registro: 
Tabela 1: Redução da Unidade de Contexto para Unidade de Registro: Análise dos dados do Sujeito 5

\begin{tabular}{|c|c|}
\hline $\begin{array}{c}\text { Unidade de Contexto } \\
\text { (segmento bruto do texto) }\end{array}$ & $\begin{array}{c}\text { Unidade de Registro } \\
\text { Redução da unidade de Contexto }\end{array}$ \\
\hline $\begin{array}{l}\text { sempre me baseio tanto em livros comb } \\
\text { no site da internet, hoje em dia, nós } \\
\text { sabemos que site de internet você tem } \\
\text { coisas tanto verdadeiras, como coisas nãß } \\
\text { tão verídicas, né? } \\
\text { Eu tenho muita influência pela internet, jz } \\
\text { tive jornal pela internet, tenho um mailing } \\
\text { enorme } \\
\text { Muitos livros; DVD's; tem que investir, } 4 \\
\text { uma arte cara; é uma arte cara! } \\
\text { as pessoas têm que estudar, seja } \\
\text { professora, seja aluna, tem que estudar } \\
\text { sempre, pesquisar sempre, fazerem cursos, } \\
\text { terem as referências corretas, cuidado com } \\
\text { o que elas pegam, onde pegam, cuidado } \\
\text { com a internet, muito cuidado com a } \\
\text { internet, muito cuidado com os vídeos no } \\
\text { "Youtube", não é porque você viu no } \\
\text { "Youtube" que aquilo ta correto }\end{array}$ & $\begin{array}{l}\text { Pode-se encontrar bases para esta dança } \\
\text { tanto na literatura quanto na internet, local } \\
\text { no qual se deve ter cautela. } \\
\text { A divulgação da dança pela internet é } \\
\text { considerada grande. } \\
\text { Apesar de ser uma arte considerada cara, é } \\
\text { possível encontrar livros e DVD's no } \\
\text { mercado. } \\
\text { Ressalta-se a importância dos estudos e os } \\
\text { meios pelos quais estes podem ser obtidos, } \\
\text { enfatizando que devem ser consideradas } \\
\text { as referências destas informações, } \\
\text { principalmente as da internet. }\end{array}$ \\
\hline $\begin{array}{l}\text { as pessoas, por exemplo, dançarem } \mathbf{D} \\
\text { bastão e com a música errada e com a } \\
\text { roupa errada e isso acontece muito, ta? } 6 \\
\text { Então as pessoas têm de saber de onde } \\
\text { elas tiraram aquilo, entendeu? }\end{array}$ & $\begin{array}{l}\text { É comum encontrar apresentações que não } \\
\text { condizem com a realidade oriental de fato. } \\
\text { Deve-se ter referências, estudos. }\end{array}$ \\
\hline $\begin{array}{l}\text { eu viajo todo ano pra fora, tanto prãa } \\
\text { estudar, quanto fazer algum tipo de } \\
\text { evento, pra dançar, porque na vida voç } \\
\text { tem que estudar sempre, sempre, sempre, } \\
\text { se atualizar, estudar, conhecer nov@ } \\
\text { formas, novas professoras, } \\
\text { mas eu tenho que estudar sempre, sempre, } \\
\text { conhecer outros estilos, outras formas pra } \\
\text { se inovar. } \\
\text { uma dedicação muito grande, incessante, } \\
\text { diária, de você ta no meio, você tem que } \\
\text { treinar, você tem que estudar, você tem } \\
\text { que assistir, você tem que divulgar, é } \\
\text { trabalho administrativo,é trabalho técnico, } \\
\text { é trabalho cultural }\end{array}$ & $\begin{array}{l}\text { O mais importante é manter-se atualizado; } \\
\text { estudar. } \\
\text { Deve-se considerar os estudos que } \\
\text { apresentem inovações. } \\
\text { Para ser uma boa profissional na área, há } \\
\text { necessidade de grande dedicação. }\end{array}$ \\
\hline $\begin{array}{l}\text { Agora a dança do ventre no mundo todd,0 } \\
\text { ela cresceu bastante, muito, muito, muito, } \\
\text { cada vez mais você encontra, em qualquetrl } \\
\text { cidade, em qualquer país, } \\
\text { Então é uma dança, uma arte que se2 } \\
\text { difundiu muito, pelo mundo todo você } \\
\text { consegue encontrar. } \\
\text { É aqui na cidade de São Paulo, por caush3 } \\
\text { da comunidade árabe, porque foi (éh), } \\
\text { porque tudo partiu daqui } \\
\text { São Paulo é a grande referência da dança } \\
\text { do ventre no Brasil }\end{array}$ & $\begin{array}{l}\text { A disseminação desta dança tem crescido } \\
\text { constantemente, num âmbito mundial. } \\
\text { Atualmente esta dança encontra-se } \\
\text { difundida por todo o mundo. } \\
\text { Considera-se que esta dança é mais } \\
\text { praticada, estudada e difundida em São } \\
\text { Paulo, pois partiu deste local, no Brasil. } \\
\text { São Paulo é a referência de dança do } \\
\text { ventre no Brasil. }\end{array}$ \\
\hline
\end{tabular}


Uma vez estabelecidas as Unidades de Registro, pudemos elaborar outras quatro tabelas, uma para cada Subcategoria estabelecida. De acordo com nossa pré-análise e leitura das transcrições, as Subcategorias que se apresentaram foram: (1) mídia; (2) posturas críticas; (3) proposições e (4) disseminação da modalidade. Explicitamos resumidamente a seguir o contexto central de cada uma dessas subcategorias.

(1) Mídia: uma hipótese inicial levantada por esse estudo, presente na introdução desse texto, é que no intervalo de dez anos que estamos analisando, graças à maior exposição da Dança do Ventre nos meios de comunicação (em especial televisão/novelas e internet), haveria uma mudança na forma de pensar e agir na modalidade. De fato, as entrevistas confirmaram essa hipótese e os trechos que ilustram essa inferência foram destacados, permitindo a redação da subcategoria Mídia.

(2) Posturas críticas: todos os entrevistados apresentaram um discurso no qual assumem uma postura crítica frente à modalidade, levandonos a estabelecer uma subcategoria que aglutina os principais sentidos dessas críticas.

(3) Proposições: todos os entrevistados apresentaram um discurso no qual assumem uma postura sugestiva em relação às mudanças e evoluções que supõem necessárias, possíveis ou inevitáveis na modalidade, levando-nos a estabelecer uma subcategoria que aglutina os principais sentidos dessas propostas.

(4) Disseminação da Modalidade: foi presença constante nas entrevistas um discurso que aborda a disseminação da Dança do Ventre em muitos contextos. Um dos objetivos principais desse estudo foi o de analisar a evolução dos modos de pensar e praticar a Dança do Ventre nos últimos dez anos, de modo que tornou-se relevante a redação da subcategoria "Disseminação da Modalidade" justamente no sentido de indicar parte dessa evolução.

A seguir, novamente a título de exemplo, apresentamos uma das quatro tabelas de redação das Subcategorias, no caso, a da Subcategoria Proposições. 
Tabela 2: Convergências de Unidades de Registro de todos os sujeitos para a redação da Subcategoria: Proposições

\begin{tabular}{|c|c|}
\hline $\begin{array}{l}\text { Convergências de Unidades de } \\
\text { Registro }\end{array}$ & Subcategoria: Sugestões \\
\hline $\begin{array}{l}\text { Observa-se a necessidade da } \\
\text { existência de critérios classificatórios para } \\
\text { qualificar as pessoas como profissionais } \\
\text { da área. } \\
\text { Considera-se que a modalidade de } \\
\text { dança em questão necessita de uma escola } \\
\text { especifica para formação de profissionais } \\
\text { devido ao grande conteúdo que esta } \\
\text { abrange. } \\
\text { As faculdades de dança não } \\
\text { comportam a formação especifica em } \\
\text { dança do ventre. } \\
\text { Nota-se falta de características } \\
\text { comportamentais como humildade e } \\
\text { respeito nas atuais profissionais. } \\
\text { Deve-se privar a educação, a } \\
\text { humildade, a generosidade e o amor nesta } \\
\text { profissão. } \\
\text { Todas as bailarinas de dança do } \\
\text { ventre devem manter-se em estudo. } \\
\text { A humildade e a generosidade } \\
\text { devem ser mantidas nesta profissão. } \\
\text { Para ser uma bailarina profissional } \\
\text { (Suj. 2) }\end{array}$ & $\begin{array}{l}\text { Esclarece-se que a melhor maneira } \\
\text { para solucionar as críticas apontadas é o } \\
\text { estudo, em todas as suas possibilidades, } \\
\text { tais quais: aulas, leituras, apreciação de } \\
\text { vídeos, cursos, apresentações, entre } \\
\text { outros. } \\
\text { A possibilidade de se criar uma } \\
\text { escola que seja capaz de formar bailarinas } \\
\text { e professoras nesta modalidade ou no } \\
\text { mínimo estabelecer pritérios } \\
\text { classificatórios para se exercer essas } \\
\text { profissões são apresentadas como } \\
\text { hipóteses. } \\
\text { As características comportamentais } \\
\text { requeridas são o respeito, a } \\
\text { humildade e principalmente } \\
\text { responsabilidade e a ética, muito embora } \\
\text { existam evidências acerca do apreço que } \\
\text { tem sido dado à estética nesta dança. } \\
\text { postura, ao condicionamento fisico e à } \\
\text { forte presença de giros na dança do ventre. } \\
\text { indicadas para se obter melhor qualidade } \\
\text { técnica da movimentacão devido à }\end{array}$ \\
\hline $\begin{array}{l}\text { Apresenta-se como ideal a } \\
\text { execução semanal de uma aula de balé } \\
\text { clássico para um bom rendimento nas } \\
\text { aulas de dança árabe. }\end{array}$ & \\
\hline
\end{tabular}

aulas de dança árabe. 


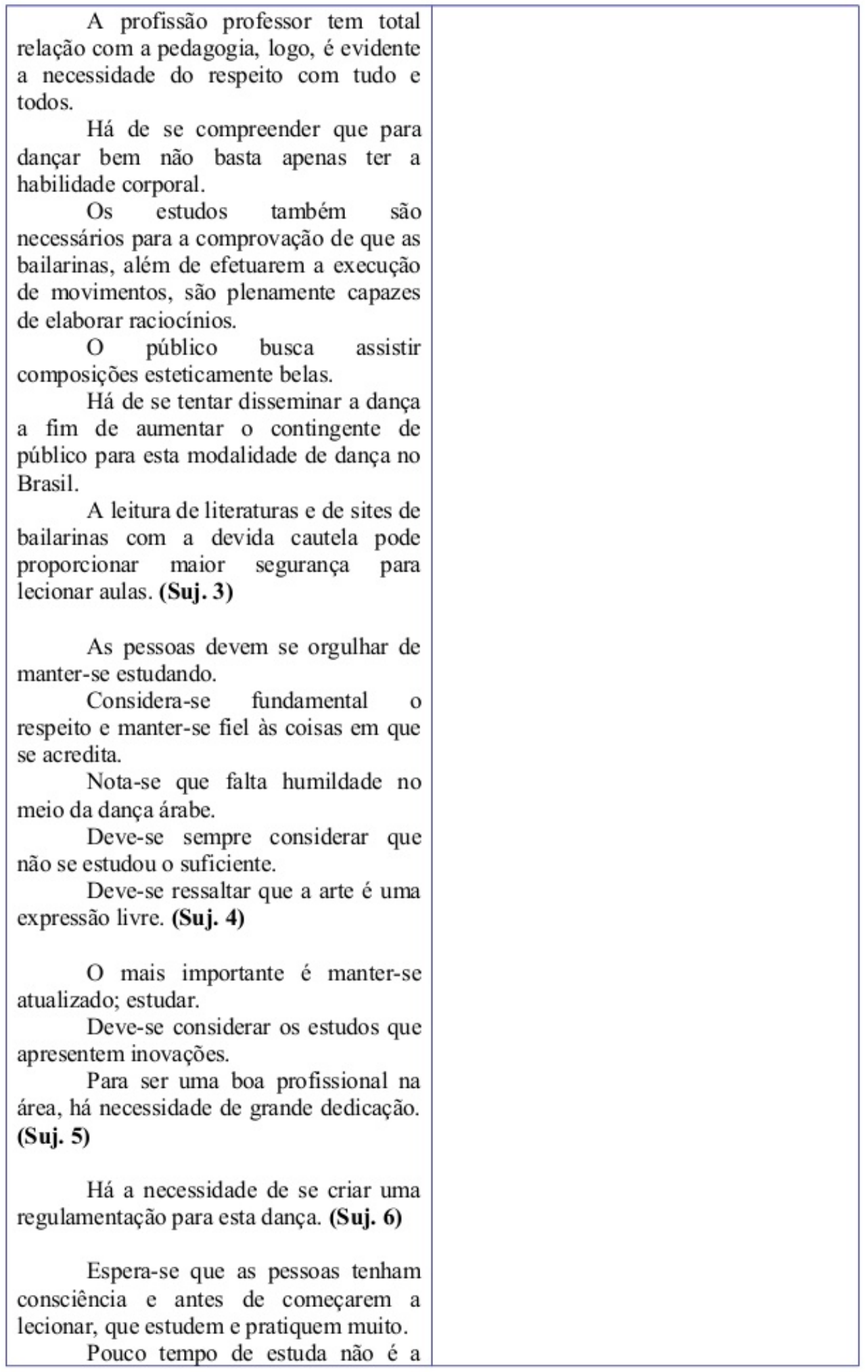




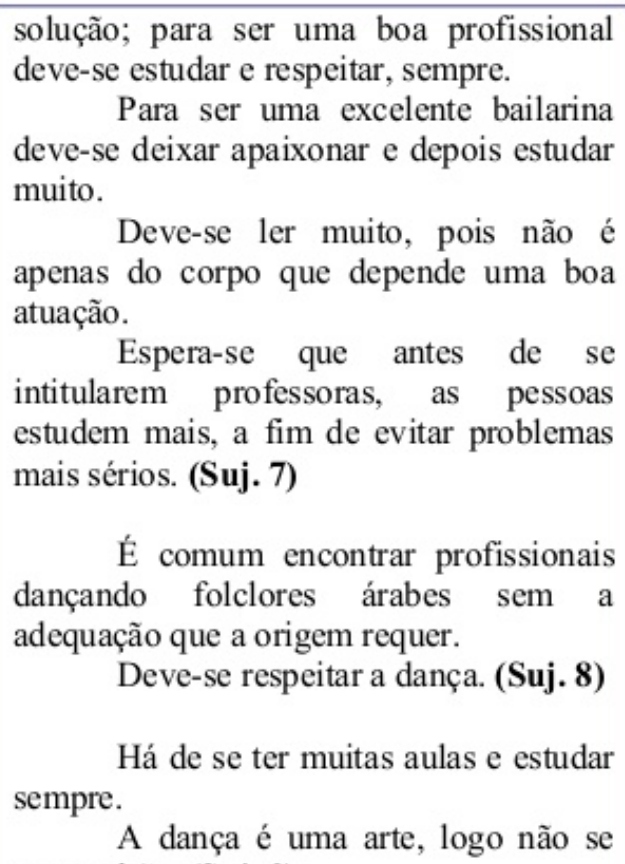

Deve-se ler muito, pois não é apenas do corpo que depende uma boa atuação.

Espera-se que antes de se intitularem professoras, as pessoas estudem mais, a fim de evitar problemas mais sérios. (Suj. 7)

É comum encontrar profissionais dançando folclores árabes sem a adequação que a origem requer.

Deve-se respeitar a dança. (Suj. 8)

Há de se ter muitas aulas e estudar sempre.

A dança é uma arte, $\log$ o não se tem padrão. (Suj. 9)

$\mathrm{O}$ volume total dos dados presentes nas quinze tabelas (onze de redução da Unidade de Contexto para Unidade de Registro e quatro de convergência de Unidades de Registro de todos os sujeitos para a redação das Subcategorias) excede a possibilidade de apresentação nesse artigo, de modo que elaboramos uma tabela com o extrato das informações obtidas nas quatro Subcategorias (mídia, posturas críticas, proposições e disseminação da modalidade). Esse extrato, em nossa metodologia, coincide com a etapa final de tratamento dos dados de modo a apresentá-los da forma mais sucinta e significativa de que foi capaz a pesquisa. A seguir, apresentamos a Tabela 3, com o extrato das informações tratadas pelo processo de análise de conteúdo das entrevistas: 
Tabela 3: Extrato das informações obtidas nas Subcategorias mídia, posturas críticas, proposições e disseminação da modalidade

\begin{tabular}{|c|}
\hline Mídia \\
\hline $\begin{array}{l}\text { A internet é considerada a forma pela qual a dança é mais difundida embora } \\
\text { ressalte-se a dificuldade de se averiguar a qualidade das fontes. } \\
\text { A novela "O Clone", exibida no ano de } 2000 \text { pela TV Globo, contribuiu para a } \\
\text { divulgação da Dança do Ventre e de modo geral forneceu um aspecto positivo acerca } \\
\text { de suas práticas. }\end{array}$ \\
\hline Posturas Críticas \\
\hline $\begin{array}{l}\text { Questiona-se o preparo específico dos profissionais envolvidos com a Dança do } \\
\text { Ventre, a falta de escolas especializadas, e problemas com a postura ética decorrente. } \\
\text { Critica-se também um excesso de glamour por parte dos praticantes. }\end{array}$ \\
\hline Proposições \\
\hline $\begin{array}{l}\text { Aponta-se, sobremaneira, a necessidade de pesquisas e capacitações para a } \\
\text { modalidade. O Balé clássico é visto como suporte metodológico possivel para a Dança } \\
\text { do Ventre em um contexto de aprendizado. }\end{array}$ \\
\hline Disseminação da modalidade \\
\hline
\end{tabular}

\section{Discussão e considerações finais}

A partir do processo de análise de conteúdo das entrevistas, assumiremos os dados da tabela de extrato como referência para nossas discussões, passando a falar genericamente dos dados obtidos e tratados como representativos dos discursos dos sujeitos.

De acordo com a análise dos dados, os entrevistados apresentaram a internet como fonte primária de informação acerca da modalidade, dizendo ser possível localizar desde vídeos até artigos científicos, contudo, sempre frisando a possibilidade de comprometimento de qualidade ou veracidade dos materiais. Ao longo dos 10 anos que essa pesquisa investiga, houve incremento substancial das informações disponíveis na internet o que, no caso da Dança do Ventre, deve ser destacado, uma vez que se trata de uma arte com origem em territórios longínquos. Alguns dos sujeitos comentaram nesse argumento que a construção de um acervo de imagens e outros materiais, durante muitos anos, foi dependente da ida de brasileiros aos países árabes ou mesmo da importação custosa e demorada de produtos.

Também declararam possuir e/ou utilizar materiais como DVD, VHS ou TV tanto como fonte de informação, quanto de divulgação e abordaram especificamente a exibição da novela "O Clone" como contribuinte para divulgação da modalidade em território nacional, independentemente de seus benefícios ou malefícios, ressaltando ain- 
da a possibilidade desta ter provocado uma sensibilização na população no que diz respeito à forma de se ver a bailarina de Dança do Ventre. Como aponta Conti et al. (2010) há uma intensa interferência da mídia em relação aos corpos dos jovens, sendo que em sua pesquisa obteve-se um índice de 95\% dos entrevistados associando TV e ideais de corpo. Uma vez que a Dança do Ventre é uma arte do corpo e, por sua vez, as novelas televisivas são propagadoras inerentes de valores e comportamentos, podemos inferir que a influência dessa novela em específico na modalidade não é um dado suplementar ou menos, mas talvez um indicador que realmente reconfigura a modalidade em nosso país.

No que diz respeito às posturas críticas assumidas pelos entrevistados, sintetizadas na Tabela 3, podemos interpretar que haja um foco na questão formativa, a partir da qual se desenvolvam outros incômodos. A falta de centros de capacitação específica para essa modalidade parece gerar, na visão dos sujeitos dessa pesquisa, tanto uma abertura para um comportamento desregrado, antiético, como também processos pedagógicos não uniformes, o que compromete a disseminação e aceitação da modalidade no mundo da dança. Efeito perverso de uma prática pouco sistematizada seria o apego excessivo aos aspectos puramente exibicionistas da dança, exacerbando o conteúdo sensual em detrimento de outros aportes presentes nessa arte. A imagem típica do senso comum sobre a Dança do Ventre teria ocupado um lugar deixado vazio pelas escolas da modalidade. Grande parte das entrevistas faz menção a possibilidades de estudos que variam entre aulas práticas e teóricas de Dança do Ventre, aprendizados em história, filosofia, fotografia, leituras, apreciação de vídeos e assim por diante.

No caminho aberto pelas críticas dos sujeitos, os mesmos são congruentes em propor que um maior volume de pesquisas, estudos e abordagens sistematizadas passem a fazer parte do processo de evolução da modalidade e da formação de dançarinas. Notando a insipiência das metodologias de ensino em Dança do Ventre muitos dos sujeitos depositam no Balé Clássico uma confiança de que o mesmo possa incrementar o aprendizado. Com frequência ele foi apresentado ou como sugestão de condicionamento para a Dança do Ventre ou como necessidade técnica para a mesma, visto que ele supostamente propicia força muscular, postura adequada e melhora da habilidade de giros. Não obstante essas qualidades técnicas realmente evidentes no Balé Clássico, talvez possamos interpretar essa alternativa apresenta- 
da como decorrente do status que desfruta o Balé no mundo da dança e de sua associação com uma rígida disciplina. Nesse cenário, talvez os sujeitos acabem por misturar causas e efeitos, supondo que a falta de metodologia evidenciada na Dança do Ventre possa ser suprida emprestando-se outra que, a priori, tem origens distintas e um vocabulário gestual muito diferente. É possível notar nos discursos, mesmo por aquilo que Bardin denomina de empatia, "a imersão no universo subjetivo do entrevistado" (p. 92), que há uma angústia presente no posicionamento desses profissionais que se observam com uma dedicação intensa a uma modalidade que, por falta de uma sistematização mais identificável como a do Balé Clássico, acabam relegados a uma impressão de prática exótica e maneirismo estético.

Assim como São Paulo foi apontada de forma uníssona como principal centro de estudos, prática e disseminação da Dança do Ventre no país, foi também unânime a certeza de que a modalidade encontra-se bem difundida atualmente, tanto em âmbito nacional, como internacional. Foram apontadas algumas regiões ou estados em que se observou maior destaque no Brasil, como Minas Gerais, Brasília e Rio de Janeiro, bem como alguns países que praticam, inclusive tendo um dos sujeitos declarado já ter visitado vinte e sete países a trabalho ou para fins de estudos sobre a Dança do Ventre. A concentração da modalidade nos grandes centros é até certo ponto evidente e parece indicar um crescimento futuro em potencial. No entanto, também reforça indiretamente o caráter exótico da modalidade, parecendo que a mesma só encontra espaço nas metrópoles, mais acostumadas à diversidade. Pelo discurso dos entrevistados, a consistência metodológica do ensino em Dança do Ventre poderia conduzir a uma disseminação mais abrangente e menos agregada ao exotismo estético. Talvez pela condição de profissionais dessa modalidade, os sujeitos são unânimes em optar mais por uma disseminação fundamentada em uma pedagogia mais homogênea do que nos prazeres estéticos de uma arte supostamente exótica, sensual ou glamourosa.

De modo sintético, podemos afirmar, à luz da comparação com os dados de Trevisan (2000), que houve sensível evolução nas formas de pensar e agir no contexto da Dança do Ventre em território nacional nos últimos dez anos, subsidiada em especial pela disseminação da modalidade, pela facilidade de acesso à informação como a propiciada pela internet e, também, pela popularização alcançada a partir de novelas e filmes. Nesse mesmo sentido, corroboram essa percepção o 
fato notável de uma construção de discursos críticos e sugestivos em torno da modalidade por parte dos entrevistados. Por tais constatações, supomos que essa pesquisa foi capaz de erigir um diagnóstico indicativo do atual contexto da modalidade, abrindo horizontes para outras intervenções que continuem a explorar a riqueza e tradição presentes nessa singular manifestação da dança.

BELLY DANCE: DEVELOPMENTS AND SUGGESTIONS FOR A DECADE

\begin{abstract}
The focus of this work is the Belly Dance. We applied an interview, consisting of two semi-structured questionnaires in eleven individuals. This initiative was intended to check whether there have been changes in the ways of thinking and acting about belly dancing - that is the reason which we interviewed only subjects with more than ten years of experience. We used the content analysis proposed by BARDIN (2010). We concluded there was a significant evolution in the ways of thinking and acting in the context of Belly Dance in the country over the past ten years, particularly subsidized by the spread of this type of dance, by the ease of access to information as provided by the Internet, and by the popularization reached from soap operas and movies. Support: CNPq.
\end{abstract}

Keywords: Dancing. Video-audio media. Esthetics.

DANZA DEL VIENTRE: EVOLUCIÓN Y PROPUESTAS PARA UNA DÉCADA

\title{
Resumen
}

Este trabajo ha enfocado la Danza del Vientre en el país durante la última década. Para ello, hemos realizado una entrevista semiestructurada a once sujetos involucrados con la modalidad desde hace más de diez años y hemos operado un Análisis de Contenido, tal como lo ha propuesto BARDIN (2010). Los resultados obtenidos demuestran una sensible evolución en las formas de concebir la estética de la Danza del Vientre en el territorio nacional en la última década, subsidiada, en especial, por la notable diseminación de la modalidad, por la facilidad de acceso a la información como la propiciada por internet y por la popularización alcanzada gracias a telenovelas y películas. Los resultados obtenidos se los comparó a los de TREVISAN (2000), de modo a obtener un indicativo más de la evolución que investigamos. Apoyo: CNPq.

Palabras clave: Danza. Medios Audio Visuales. Estética.

\section{Referências}

BARDIN, L. Análise de Conteúdo. Editora: Edições 70, 2010. 
BÉRGAMO, E. Dança do ventre da FEF: conhecimentos envolvidos e desenvolvidos nesta atividade de extensão. 2003. $73 \mathrm{f}$. Trabalho de Conclusão de Curso (Graduação em Educação Física)-Faculdade de Educação Física, Universidade Estadual de Campinas, Campinas, 2003.

CANTUSIO, C. A. Dança do ventre: a arte de ser mulher. Campinas: Editora Komedi, 2003.

CENCI, C. A dança da libertação. São Paulo: Vitória Régia, 2001.

CONTI M. A; TORAL N.; PERES S. V. A mídia e o corpo: o que o jovem tem a dizer. Ciência \& Saúde Coletiva, Rio de Janeiro, v. 15, n. 4, p. 2095-2103, jul., 2010.

FERREIRA, A.B.H. Miniaurélio: o minidicionário da língua portuguesa. 7. ed. Curitiba: Positivo, 2008.

FRANZOSI, N. M. Dança do Ventre: um olhar da educação física. 2009. 84 f. Trabalho de Conclusão de Curso (Graduação em Educação Física)-Escola de Educação Física e Esporte, Universidade de São Paulo, São Paulo, 2009.

GIL, A. C. Como elaborar projetos de pesquisa. 3. ed. São Paulo: Atlas, 1991.

LA REGINA, G. Dança do ventre: uma arte milenar. São Paulo: Moderna, 1998.

MARATÓ, M. H. Bailar La Danza Del Vientre. Madri: Mandala Ediciones, 2006.

MARTINS, L.F.A. Ventre que encanta. São Paulo: Nijme. 2005.

MOHAMED, S. La Danza Mágica Del Vientre. Madri: Mandala Ediciones, 1995.

PENNA, L. Dance e recrie o mundo: a força criativa do ventre. 4. ed. São Paulo: Summus Editorial, 1993.

TREVISAN, C. S. Dança do ventre: considerações sobre a sua história e o seu ensino. 2000. 146 f. Trabalho de Conclusão de Curso 
(Graduação em Educação Física)-Faculdade de Educação Física, Universidade Estadual de Campinas, Campinas, 2000.

Recebido em: 27/09/2012

Revisado em: 12/11/2012

Aprovado em: 18/02/2013

Endereço para correspondência

roble@fef.unicamp.br

Odilon José Roble

Universidade Estadual de Campinas, Faculdade de Educação Física.

Rua Érico Veríssimo

Barão Geraldo

13083851 - Campinas, SP - Brasil 